\title{
Anotações sobre a teoria feminista do direito de Catharine MacKinnon
}

\author{
Notes on Catharine MacKinnon's legal theory
}

\author{
${ }^{1}$ Ligia Maria Ladeira Tavares \\ ${ }^{2}$ Cecília Caballero Lois
}

\section{RESUMO}

Este artigo objetiva introduzir as ideias gerais da teoria do direito de Catharine MacKinnon, desenvolvida sob as premissas do feminismo radical, que concebe a subordinação das mulheres não como decorrência das desigualdades jurídica e política, mas sim, de uma política sexual implementada pela ideologia patriarcal, inclusive no âmbito do Estado. O direito, sob a perspectiva feminista, não é neutro, mas masculino em sua criação, interpretação e aplicação, como reflexo do sistema de dominação sexual. O reconhecimento da ausência de neutralidade do direito constitui ponto chave para a construção de uma teoria apta a permitir o alcance da cidadania pelas mulheres.

Palavras-chave: Teoria feminista. Feminismo radical. Catharine MacKinnon.

\begin{abstract}
This article aims to introduce the general ideas of Catharine MacKinnon's legal theory, developed under the premises of radical feminism, which conceives the subordination of women not as a result of legal and political inequalities, but rather a sexual policy implemented by the patriarchal ideology, including within the State. Law, under the feminist perspective, is not neutral, but masculine in its creation, interpretation and application, reflecting the sexual domination system. The recognition of law's lack of neutrality constitutes key to building of a theory capable to allow the scope of citizenship by women.
\end{abstract}

Keywords: Feminist theory. Radical feminism. Catharine MacKinnon.

\footnotetext{
${ }^{1}$ Mestranda em Teorias Jurídicas Contemporâneas pelo Programa de Pós-graduação em Direito da Universidade Federal do Rio de Janeiro (UFRJ), Cidade Universitária, Rio de Janeiro, Brasil. Email: ligitavares@ gmail.com

${ }^{2}$ Mestre e Doutor em Direito pela Universidade Federal de Santa Catarina (UFSC), Florianópolis, Santa Catarina . Pós-doutora pela Pontifícia Universidade Católica do Rio de Janeiro (PUC-RJ). Professora dos Cursos de Graduação e Pós-graduação em Direito da Universidade Federal do Rio de Janeiro (UFRJ) e Coordenadora Adjunta do Programa de Pós-graduação em Direito da Universidade Federal do Rio de Janeiro (UFRJ), Cidade Universitária, Rio de Janeiro, Brasil. Email: cecilialois@ gmail.com
} 


\section{INTRODUÇÃO}

O motivo para a elaboração deste artigo foi a escassez de material encontrado em língua portuguesa ou em referências de trabalhos nacionais acerca das ideias que formam a teoria feminista do direito Catharine MacKinnon, figura de destaque no pensamento feminista contemporâneo inspirada pelo feminismo radical.

Advogada, professora de Direito na Universidade de Michigan e ativista em questões de igualdade entre os sexos, MacKinnon foi pioneira na obtenção do reconhecimento judicial do assédio sexual como forma de discriminação sexual ${ }^{3}$, bem como na aceitação de sua concepção da pornografia como violação aos direitos humanos das mulheres ${ }^{4}$.

Seu trabalho se concentra nas diferenças entre as condições socioeconômicas das mulheres tanto no âmbito privado como no público e considera que a sociedade, embora perceba essas diferenças, entende-as como naturais e recusa a existência de uma verdadeira hierarquia sexual que coloca os homens em posição privilegiada.

Diante da importância da contribuição teórica de MacKinnon para a política e o direito, este trabalho, que não se pretende original nem definitivo, tem a finalidade de preencher algumas lacunas sobre a construção de seu pensamento ao apresentar suas ideias centrais e contribuir para o debate no Brasil.

Para a compreensão com que este artigo pretende colaborar, será examinada na primeira parte a trajetória dos movimentos de mulheres desde o enfrentamento da doutrina das esferas separadas da era vitoriana até o feminismo liberal e o radical contemporâneos. Na segunda parte

\footnotetext{
${ }^{3}$ O livro "Sexual harassment of working women", escrito por MacKinnon e publicado no ano de 1979, foi inovador ao trazer a noção de relações assimétricas de poder entre homens e mulheres e influenciou o tratamento a ser dado a partir de então pelo direito aos casos de assédio sexual. No ano de 1986, a Suprema Corte dos Estados Unidos acolheu a teoria de MacKinnon no caso Meritor Savings Bank FSB v. Vinson, 477 U.S. 57 (1986) e decidiu que o assédio sexual violava o Título VII do Civil Rights Act de 1964, que proibia a discriminação no mundo do trabalho com base em raça, cor, religião, sexo e origem nacional.

${ }^{4} \mathrm{Em}$ "The reasons why: essays on the new civil rights law recognizing pornography as sex discrimination", escrito em conjunto com a ativista feminista Andrea Dworkin, MacKinnon se posiciona contrariamente à indústria da pornografia por entendê-la como terrorismo praticado contra mulheres e explicitação gráfica da subordinação sexual. Também com Andrea Dworkin, elaborou projetos de lei aprovados em Indianápolis, Indiana e Minneapolis, Minnesota, nos Estados Unidos, que autorizavam processar os criadores e negociantes de pornografia caso fosse provado que uma mulher ou as mulheres como grupo tivessem suportados danos decorrentes da pornografia.
} 
será apresentada a teoria do direito de Catharine MacKinnon e, especificamente, sua visão sobre as implicações do crime de estupro em uma sociedade patriarcal. Por último, serão expostas as conclusões deste estudo acerca do papel do direito em relação à subordinação das mulheres.

\section{Dos movimentos políticos iniciais ao feminismo contemporâneo}

Esta primeira parte situa historicamente, dentro dos limites deste trabalho, os movimentos de mulheres do século XIX, centrados na disputa por maior participação no espaço público mediante a invocação do direito à igualdade, e os movimentos feministas contemporâneos.

\subsection{Esferas separadas e cavalheirismo: cenário para o feminismo "avant la lettre"}

O contexto social e cultural do fim do século XIX e do início do século XX era de intensa repressão sexual e obedecia aos rígidos padrões de comportamento da sociedade liberal burguesa da era vitoriana, cuja moralidade se pautava pela adoção de esferas separadas de vida: às mulheres cabe o cuidado com o lar, o marido e os filhos, ao passo que aos homens, o mundo exterior ao doméstico.

Em relação à política e à economia, o liberalismo clássico consolidado a partir da Revolução Francesa pregava a primazia da liberdade individual sobre o Estado, a limitação do poder estatal por meio de normas jurídicas, a igualdade de todos perante a lei e a propriedade privada.

Toda essa liberdade, porém, não daria guarida a todos os indivíduos, uma vez que as mulheres estavam afastadas da oportunidade de usufruir a expansão do livre mercado e a autonomia privada (PERROT, 2010), conforme a doutrina das esferas separadas, largamente exposta em "Of the Queen's Gardens” de John Ruskin, publicado em 1864. A obra fornecia uma explicação para o confinamento ao espaço doméstico com base na natureza ao apresentar o interesse nas tarefas relacionadas à família e ao lar como da essência das mulheres e, com isso, representava a impossibilidade de sua emancipação social e política. (MILLETT, 2016)

Noções essencialistas, portanto, indicariam que a mulher atingiria o ápice de sua existência como ser humano ao permanecer circunscrita ao lar e, desde tal lugar, fornecer suporte moral ao marido, caso fosse necessário. 
O cavalheirismo, como política adequada ao padrão de moralidade ditado pela doutrina das esferas separadas, empregava a prática de atitudes gentis e protetivas superficialmente favoráveis às mulheres (burguesas), que seriam naturalmente seres frágeis e dependentes 5 .

Assim, as mulheres não deveriam desejar se educar, pois não seria necessário às suas atribuições naturais; não deveriam desejar trabalhar, pois o trabalho remunerado fora do lar seria naturalmente atribuído ao homem; e não deveriam desejar votar, pois a participação política não cabia nas limitações naturais femininas.

A doutrina das esferas separadas e a política cavalheiresca tinham por tática criar um consenso de que a vida doméstica e o luxo seriam os objetivos das mulheres "de bem", os quais seriam atingidos somente pelo casamento, obscurecendo a percepção de que a reclusão ao espaço privado consistia em verdadeira imposição social e não, na realização de um impulso inato. (MILLETT, 2016)

Contra a doutrina das esferas separadas e o cavalheirismo como justificativas naturais, John Stuart Mill, em seu "The subjection of women", publicado em 1869, denunciou que a subordinação das mulheres nas esferas pública e privada contrariava, além da prevalência moral do indivíduo em relação à coletividade, do universalismo, da igualdade e "do progresso acompanhado por um sistema de igualdade de oportunidades” (BELTRÁN et al., 2012, p. 52, tradução nossa), também o princípio utilitarista da maximização da satisfação total, pois a participação feminina no livre mercado beneficiaria toda a sociedade ${ }^{6}$.

Na visão de Mill, as mulheres seriam um produto de um sistema de opressão, na medida em que sua educação limitada e as restrições jurídicas impostas à sua liberdade e à sua propriedade seriam mecanismos de perpetuação de uma situação de subordinação nociva a toda a sociedade.

\footnotetext{
${ }^{5}$ É clássica a fala de Sojourner Truth, abolicionista e ex-escrava norte-americana, ao responder a um clérigo que dissera que mulheres não deveriam ter direitos por serem fisicamente frágeis e indefesas: "Aquele homem diz que mulheres precisam ser ajudadas a subir em carruagens, carregadas sobre poças e ter o melhor assento em qualquer lugar. Ninguém nunca me ajudou a subir em carruagens, atravessar poças ou me deu o melhor lugar - eu não sou uma mulher? Olhem para este braço! Lavrei, plantei e recolhi aos celeiros e nenhum homem me conduziu - eu não sou uma mulher? Eu podia trabalhar e comer tanto quanto um homem - quando conseguia - e suportar o chicote também! Eu não sou uma mulher? Dei à luz treze crianças, vi a maioria delas ser vendida como escrava e quando chorei pela minha dor de mãe ninguém a não ser Jesus me ouviu. Eu não sou uma mulher?" (STANTON; ANTHONY; GAGE, 1889, p. 116 apud MILLETT, 2016, posição 2.197, tradução nossa)

${ }^{6}$ Em razão da limitação deste estudo não cabe o aprofundamento na obra de Mill, mas é preciso destacar que sua utilitarista de Mill apresenta uma novidade ao liberalismo ao concluir que o cálculo da felicidade total da sociedade será obtido pelo somatório da felicidade individual de seus integrantes.
} 
Assim, uma vez que a ampliação dos direitos das mulheres conduziria à maior satisfação social e não feriria a liberdade individual de terceiros, deveria ser implementada.

Nesse cenário desenrolou-se a primeira fase da revolução sexual, que buscou alterar as concepções de temperamento, papel e status dos sexos constituídos pela ideologia patriarcal, entendida esta como um conjunto de ideias que altera a realidade ao naturalizar a desigualdade entre os sexos e promove a supremacia dos homens em prejuízo das mulheres. O tripé da luta das mulheres guiadas pelo liberalismo do século XIX era composto por educação, voto e trabalho.

Quanto à educação, esta passou a ser vista com tolerância pelos maridos interessados em mulheres que pudessem cuidar melhor do lar, desde que tal não implicasse ameaça à supremacia masculina, ao mesmo tempo em que o aumento do número de instituições educacionais de ensino primário e secundário trouxe a necessidade de fornecer às mulheres, que seriam professoras, formação educacional superior para que pudessem transmitir conhecimentos às crianças. (MILLETT, 2016)

O direito ao voto foi alcançado depois que as mulheres se uniram politicamente contra a escravidão e levaram as práticas do movimento abolicionista para o feminista, a exemplo de constantes manifestações públicas para impedir que o movimento sufragista, pautado pela igualdade política e jurídica entre homens e mulheres, caísse no esquecimento.

Em relação ao trabalho, a partir do momento em que as condições precárias impostas às mulheres (historicamente utilizadas como mão de obra de reserva, não organizada e barata, inclusive em trabalhos penosos) começaram a repercutir negativamente na família - espaço do qual as mulheres não chegaram a se afastar - foram criadas normas jurídicas protetivas cuja preocupação central não era garantir o respeito aos direitos humanos das trabalhadoras, mas sim, causar o menor distúrbio possível aos cuidados com o lar e a família. (MILLETT, 2016)

Pode-se perceber, portanto, que a chegada das mulheres à educação, ao voto e ao trabalho não se deveu a uma ruptura com a ideologia patriarcal, mas sim, a uma acomodação do patriarcado - como sistema de dominação masculina instituído pelo exercício do poder em âmbito privado e público de forma hierárquica sobre as mulheres - às demandas feministas.

Ainda assim, a revolução sexual animada pelas ideias liberais proporcionou melhora para as vidas das mulheres e, depois de algumas décadas de silêncio imposto pela reação conservadora que restabeleceu o afastamento das mulheres da educação e a doutrina das esferas separadas, recobrou seu fôlego a partir da década de 60 do século XX com o feminismo liberal. 


\subsection{O feminismo liberal da segunda metade do século XX}

O exame do feminismo liberal tem lugar neste trabalho porque o desenrolar de suas táticas políticas dará ensejo ao desenvolvimento de uma nova perspectiva feminista: o feminismo radical, sob cujas luzes MacKinnon elabora sua teoria. Para isso, é preciso estabelecer o que se pode entender como feminismo liberal, sem esquecer que suas primeiras vozes defenderam interesses da classe burguesa e exigiam direitos iguais aos dos homens.

O pressuposto do feminismo liberal dos anos 60 do século XX foi a racionalidade como atributo de um sujeito neutro e universal que poderia ser de qualquer sexo. Sob a influência do liberalismo clássico, a igualdade, com a garantia formal de tratamento igualitário como meio de aumentar no espaço público a participação das mulheres, foi o fundamento utilizado para o alcance de maior participação das mulheres no mundo do trabalho exterior à esfera privada, com atenção especial para pessoas em uma posição social desvantajosa. (BELTRÁN, et al. 2012)

Porém, a obtenção de garantias legais (p. ex., a proteção da mulher no mercado de trabalho e o controle da reprodução) que levariam ao fim da desigualdade entre os sexos, inclusive por meio de ações afirmativas para aumentar a presença de mulheres na vida pública em condições paritárias às dos homens, não acarretou o resultado desejado, mas sim, aumentou a carga de tarefas.

Apenas dez anos depois, com a união entre teoria política e prática feministas - que refletiu a importância de se ter em conta a voz das mulheres na análise da própria situação -, o feminismo adentra também o campo do direito por meio da promoção da prática jurídica feminista voltada para casos individuais apresentados ao Judiciário com fundamento nos direitos das mulheres, assim compreendidos como aqueles relacionados a situações enfrentadas especificamente por tal grupo. (BELTRÁN et al., 2012)

A tática do feminismo liberal deste período foi a busca da mudança por meio da legislação ou do litígio judicial, com base em argumentos que pudessem persuadir os agentes do poder presentes nas instituições públicas. A articulação se deu em torno dos precedentes existentes sobre discriminação racial, uma vez que a igualdade seria um pressuposto da mudança social tanto em relação à raça como ao gênero. A igualdade, assim, foi definida como tratamento similar de 
indivíduos similares. "A chave para as vitórias jurídicas iniciais da segunda onda do feminismo foi a afirmação de que mulheres e homens eram indivíduos similares para todos os fins juridicamente relevante". (WHITMAN, 1991, p. 494, tradução nossa)

Entretanto, a luta liberal por maior participação das mulheres na esfera pública com base na igualdade não resolveu o problema da subordinação, que encontra na esfera privada o terreno mais fértil para a dominação masculina ${ }^{7}$, conforme sustentaria o feminismo radical em momento posterior ao situar no lar a violência, o estupro e a exploração do trabalho das mulheres.

\subsection{0 feminismo radical como respostas às pretensões liberais}

O feminismo radical, ao entender que a igualdade cara ao feminismo liberal não fora suficiente para eliminar a situação inferior das mulheres em relação aos homens, já que as demandas por maior participação na vida pública e igualdade jurídica e política não alteraram a estrutura das relações de poder $^{8}$, conclui que o patriarcado - sistema escorado nas diferentes socializações aplicadas a mulheres e homens a partir da sexualidade, com benefícios para os últimos em prejuízo das primeiras - seria a causa da subordinação feminina.

Na perspectiva radical, a desigualdade consiste em um modo de atuação do patriarcado, que põe em prática a separação hierárquica entre os sexos para atender a propósitos políticos.

\footnotetext{
${ }^{7}$ Aqui ganha relevo o artigo intitulado "The personal is political", de Carol Hanisch, por meio do qual a autora chama atenção para sua constatação de que problemas pessoais são problemas políticos, no sentido de se formarem no contexto das relações de poder entre homens e mulheres também no âmbito privado e serem compartilhados de modo geral pelo grupo das mulheres. Assim, as soluções deveriam partir de ações coletivas de emancipação feminina e não, individualistas. (HANISCH, 1970)

${ }^{8}$ Um dos problemas da estratégia da igualdade pode ser exemplificado pelo caso de Lillian Garland, uma recepcionista do banco California Federal Savings and Loan Association da Califórnia (CalFed), que deu à luz uma criança em 12 de fevereiro de 1982 e, ao retornar ao trabalho, mesmo dentro do período de quatro meses previsto para a garantia de emprego pela lei estadual da Califórnia, foi informada de que seu cargo fora ocupado. Garland ajuizou uma ação para obter o restabelecimento de seu emprego com base na lei estadual da Califórnia, ao passo que o CalFed, em resposta, iniciou um processo para invalidar a lei estadual, que previa tratamento especial para empregadas grávidas, sob o argumento de que a lei federal (PDA - Pregnancy Discrimination Act de 1978), que determinava o tratamento igual de todos os empregados, prevaleceria sobre aquela. Antes de a Suprema Corte dos Estados Unidos apreciar a questão e julgar a favor de Garland, em California Federal S. \& L. Assn. v. Guerra, 479 US 272 (1987), o juiz Manuel L. Real chegou a declarar a lei californiana incompatível com a federal ao aceitar a tese do CalFed de que exigir a concessão de licenças com garantia de emprego para casos de incapacidade física temporária por gravidez seria uma forma de discriminação sexual a privilegiar mulheres com tratamento especial, pois homens com incapacidade física temporária por outras causas não tinham direito à idêntica garantia. A discussão central era definir se a lei e mundo do trabalho deveriam tratar mulheres e homens de forma igual ou se acomodar à singularidade da capacidade reprodutiva das mulheres trabalhadoras, condição fisiológica nunca compartilhada pelos homens trabalhadores. (VOGEL, 1990) A propósito, o enquadramento da gravidez como incapacidade é, em si, sintomático da perspectiva hegemônica masculina que será mais bem exposta ao longo do texto.
} 
Assim, "homem" e "mulher" não são categorias naturais, mas sim, políticas, com comportamentos, desejos e características moldados culturalmente.

A subordinação das mulheres decorre de uma política sexual, inclusive no âmbito do Estado, compreendida como um mecanismo de poder construído no contexto social e cultural e operacionalizado pelo patriarcado por meio da separação das estruturas humanas a partir dos sexos, com supremacia do masculino sobre o feminino.

Para os interessados na manutenção do patriarcado, homens e mulheres adotam diferentes valores e comportamentos em virtude de sua própria natureza diferenciada, que atuaria de forma distinta e específica sobre o papel, o status e o temperamento das pessoas dos sexos masculino e feminino.

Para o feminismo radical, entretanto, valores e comportamentos diferentes são produto de uma dinâmica cultural de subordinação e dominação que se perfaz de acordo com o sexo de cada pessoa desde o seu nascimento, cabendo aos integrantes do grupo dos homens a superioridade hierárquica em relação às integrantes do grupo das mulheres. (MILLETT, 2016)

A partir do estabelecimento das posições de cada um dos grupos em oposição, o dominante constrói um edifício de legitimação para perpetuação de sua condição ao mesmo tempo em que reforça o status do subordinado, providências conduzidas desde o interior das instituições ${ }^{9}$, dentro das quais se encontra o direito.

Assim, a perspectiva dominante na relação de poder é difundida como conhecimento objetivo e verdadeiro, embora seja uma justificação racional das estratégias postas em prática e não, resultado da evolução neutra do conhecimento. $O$ androcentrismo, orientação voltada a interesses específica ou tipicamente masculinos, influencia o saber científico desde a maneira de se identificar um problema, até a escolha do método de pesquisa e a forma de se interpretarem os dados encontrados ${ }^{10}$. (LANGTON, 2005)

\footnotetext{
${ }^{9}$ Pode ser ilustrativa desta afirmação a equipe ministerial do presidente interino da República, Michel Temer, conforme publicação jornalística de 12 de maio de 2016, formada exclusivamente por homens, o que eliminou a representatividade de mulheres no primeiro escalão do governo brasileiro. Disponível em: <http://especiais.g1.globo.com/politica/2016/ministros-temer/>. Acesso em: 10 de agosto de 2016.

${ }^{10}$ Sem pretender discorrer sobre tema específico da prostituição, pode-se pensar que em vez de se perguntar "Por que as mulheres 'vendem' seus corpos?" o questionamento poderia ser "Por que os corpos das mulheres são 'comprados'?" ou "Quem compra os corpos das mulheres?"
} 
A posição favorecida e o discurso da realidade objetiva (não reconhecida como apreendida desde um ponto de vista situado) permitem a conformação generalizada dos comportamentos tanto masculinos como femininos, estes a serviço daqueles e não, apenas diferenciados.

Nesse sistema de supremacia masculina, a inferioridade hierárquica da mulher, que independe de requisitos de classe, raça, etnia, orientação sexual, aspecto físico ou grau de utilização de capacidade física, não é acessória, mas estrutural ao próprio sistema, que prejudica algumas em intensidade maior ou menor a depender da categoria específica a que pertençam.

Como armas na luta política pela supremacia masculina, entendendo-se o vocábulo "política" como "relações estruturadas pelo poder, de arranjos pelos quais um grupo de indivíduos é controlado por outro" (MILLETT, 2016, posição 997, tradução nossa), o patriarcado atribui condições inferiores às mulheres nos campos econômico, social, psicológico, emocional e também jurídico.

O feminismo radical, assim, começa a questionar se o direito realmente prevê uma moldura neutra de comportamento que considera diversas perspectivas ${ }^{11}$ ou "se os métodos de análise jurídica necessariamente distorciam o que estava em jogo para as mulheres". (WHITMAN, 1991, p. 494, tradução nossa)

O sistema jurídico então passa a ser analisado em suas normas formais; nos discursos nos quais essas normas estão inseridas e de acordo com os quais foram criadas; nas instituições que, na prática, implementam e administram essas normas e na maneira pela qual são implementadas e administradas, especialmente as instituições de ensino incumbidas de transmitir a cultura jurídica; e nos atores do campo jurídico. (DALTON, 1989, p. 2)

Todo esse material é investigado a partir do ponto de vista e das experiências das mulheres, tradicionalmente ignoradas ou silenciadas pela teoria do conhecimento, que foi (e é) desenvolvida em um contexto de hegemonia masculina, dado que interfere na verificação que se pretende puramente objetiva e que, sob o manto da neutralidade, mascara o viés de quem analisa.

\footnotetext{
${ }^{11}$ Esta parece ser a concepção do feminismo liberal, linha teórica que busca a emancipação feminina a partir da
} extensão às mulheres das estruturas jurídicas e políticas construídas historicamente pelo grupo dos homens. 


\title{
20 pensamento de Catharine MacKinnon
}

A teoria feminista de MacKinnon, construída sobre as bases do feminismo radical ${ }^{12}$, sustenta que homem e mulher são criados por meio da erotização da dominação e da submissão, tocando aos homens a dominação e às mulheres, a submissão, e que para que essa dinâmica seja posta em movimento é preciso que o dominante veja no subordinado um objeto e não, um sujeito.

\begin{abstract}
Assim como a expropriação organizada do trabalho de alguns em benefício de outros define uma classe (trabalhadores), a expropriação organizada da sexualidade de alguns para o uso de outros define o sexo (mulheres). A heterossexualidade é sua estrutura social, o desejo sua dinâmica interna, gênero e família suas formas cristalizadas, os papéis sexuais suas qualidades generalizadas para as personas sociais, a reprodução uma consequência e o controle seu problema. (MACKINNON, 1989, p. 3-4, tradução nossa)
\end{abstract}

Assim, quem define o que é o objeto "mulher" é o sujeito "homem" e essa perspectiva epistemológica (masculina) se estende por todas as áreas, tornando o ponto de vista masculino o ponto de vista objetivo. Se todo o conhecimento foi construído em um contexto de supremacia masculina, então foi o olhar masculino que orientou a produção do conhecimento humano.

Afirmar a existência de objetividade, compreendida como um ponto de vista universal, não situado em nenhuma posição, é recusar o reconhecimento de que a desigualdade entre os poderes atribuídos aos sexos masculino e feminino interfere na construção da realidade pelo ponto de vista do dominante. (MACKINNON, 1983)

O feminismo vem da experiência material das mulheres e não se pretende neutro, mas sim, anuncia claramente seu ponto de vista ao mesmo tempo em que denuncia que o conhecimento neutro e objetivo é, na verdade, o conhecimento construído sob a perspectiva dos homens como grupo dominante. Disso decorre a sinalização da invisibilização da perspectiva das mulheres e o fortalecimento de nossas vozes como práticas centrais.

Para MacKinnon, o feminismo radical é o único feminismo, pois não teria se valido de outras teorias políticas originalmente formuladas sem atenção para a situação das mulheres e,

\footnotetext{
${ }^{12}$ Podem ser consideradas centrais ao feminismo radical as seguintes noções: 1) não existem aptidões inatas a cada sexo, exceto por gravidez, gestação, parto e amamentação, que são exclusividade das pessoas do sexo feminino; 2) a ideologia patriarcal conforma temperamento, papel e status de cada um dos sexos para a manutenção do sistema de supremacia masculina; 3 ) o fim da subordinação das mulheres depende do fim das diferentes socializações a partir do sexo; e 4) a esfera privada é o primeiro lugar de exercício de dominação masculina e, portanto, tem conteúdo político.
} 
metodologicamente, é pós-marxista, pois surge das condições concretas de todas as mulheres enquanto grupo, buscando identificar as semelhanças das situações das mulheres sem admitir que todas sejamos iguais. De acordo com a metodologia pós-marxista que MacKinnon vê como indissociável do feminismo radical, a relação entre Estado e sociedade deve ser analisada sob a óptica de uma teoria da determinação social de acordo com a especificidade dos sexos.

Tal não foi feito pela teoria liberal, que tratou o direito como produto da mente da sociedade e o Estado "como um árbitro neutro entre interesses conflitantes" (MACKINNON, 1983, p. 642, tradução nossa), tampouco pela teoria marxista tradicional, que viu o direito como instrumento legitimador da ideologia da classe da qual o Estado retira seu poder.

O liberalismo, quando utilizado em prol das mulheres, deu resposta às demandas formuladas com a expansão de direitos já conferidos aos homens, de forma abstrata e geral, sem analisar os resultados concretos das modificações em relação aos sexos; o marxismo, em relação às mulheres, parece quase dissipar qualquer chance de emancipação a partir do Estado.

Por não dispor de uma teoria própria (até a elaboração do feminismo radical), o feminismo transitou entre contar com o Estado como primeiro recurso de melhoria da situação das mulheres, embora sem muita estratégia para alcance e conservação de tal objetivo, ou somente com a sociedade civil (MACKINNON, 1983), tão organizada sob a visão masculina quanto o Estado.

Algumas práticas feministas têm se mostrado contraditórias em pontos-chave para a emancipação das mulheres, a exemplo de demandas pelo recrudescimento da punição por estupro baseadas na ideia de que o estuprador é alguém que praticou um ato representativo exclusivamente de violência e não aceito pela sociedade, sem enfrentar a constatação de que a violência contra mulheres é a manifestação da agressividade e da dominação sexual que são socialmente atribuídas ao sexo masculino.

O liberalismo e o marxismo, afirma MacKinnon, não entendem a violência contra a mulher como parte do sistema patriarcal e não questionam o papel do Estado (e do direito) nesse sistema. Somente o feminismo radical indaga sobre o que significa o Estado para as mulheres. (MACKINNON, 1983)

Na concepção do feminismo radical, o Estado não reflete neutralidade e objetividade, mas sim, a visão de uma sociedade cujas instâncias de poder são controladas pelo grupo dos homens e cujas estruturas ele reproduz, extraindo desse espelhamento sua legitimação. O direito, enquanto produto do Estado, reforça a divisão do poder que já existe na sociedade patriarcal e a traduz como 
objetividade científica, denominando-a de teoria do direito quando o que se tem é teoria masculina do direito ${ }^{13}$.

O Estado liberal, coercitiva e autoritariamente, constitui a ordem social no interesse dos homens como gênero, por meio suas normas legitimadoras, da relação com a sociedade e de políticas materiais. Ele alcança esse objetivo por meio da incorporação e da reafirmação do controle masculino sobre a sexualidade feminina em todos os níveis, ocasionalmente suavizando, qualificando ou proibindo juridicamente seus excessos quando necessário para a normalização. (MACKINNON, 1983, p. 644, tradução nossa)

É essencial para esse propósito de dominação a insistência na separação entre público, que toca ao Estado, e privado, que toca aos indivíduos e consistiria em um espaço de inviolabilidade até mesmo frente ao Estado. Contudo, no patriarcado, a exclusão do Estado do âmbito privado não implica emancipação feminina, já que é a primeira esfera de restrição das mulheres. Manter a liberdade em um espaço de confinamento é um paradoxo invencível.

Podemos utilizar o exemplo da violência sexual para vislumbrar as implicações práticas do pensamento de MacKinnon em uma sociedade moldada à ideologia patriarcal, que terá no Estado o redator das normas jurídicas que submeterão as necessidades das mulheres como grupo subordinado às necessidades dos homens como grupo dominante.

\subsection{O estupro e a dominação sexual}

Para o feminismo liberal, o estupro é exclusivamente um ato de violência física desviante que se manifesta por meio da sexualidade e não, um ato sexual relacionado com a dinâmica

\footnotetext{
${ }^{13}$ Ao tratar do sistema de pensamento dualista e sua associação de determinadas características ao masculino e de outras ao feminino, Olsen (1998) afirma categoricamente que o direito possui um sexo — o masculino —, uma vez que as mulheres foram historicamente afastadas dos processos de criação jurídica. "O direito se identifica com os lados hierarquicamente superiores e "masculinos" dos dualismos. Embora a "justiça" seja representada como uma mulher, segundo a ideologia dominante o direito é masculino e não, feminino. Supõe-se que o direito seja racional, objetivo, abstrato e universal, tal como os homens consideram a si mesmos. Ao contrário, supõe-se que o direito não seja irracional, subjetivo ou personalizado, tal como os homens consideram sejam as mulheres. As práticas sociais, políticas e intelectuais que constituem o direito foram durante muitos anos levadas a cabo quase exclusivamente por homens. Uma vez que as mulheres foram por muito tempo excluídas das práticas jurídicas, não surpreende que os traços associados às mulheres não sejam muito valorizados no direito. De outro lado - como uma espécie de círculo vicioso - considera-se que o direito seja racional e objetivo, entre outras coisas, porque é valorizado e que seja tão valorizado por ser considerado racional e objetivo". (OLSEN, 1998, p. 693, tradução nossa)
} 
dominação-subordinação. Sua motivação não seria sexual e o pênis funcionaria tão-somente como uma arma para a prática da violência física.

Para MacKinnon (1983), cuja compreensão vem das vozes das vítimas, o sexo forçado, no patriarcado, é o paradigma do poder masculino, já que a agressividade e a dominação compõem o próprio centro da sexualidade masculina. Assim, o estupro pode ser sexual justamente por ser violento.

A concomitância de sexualidade com violência, fomentada para obscurecer a realidade de que os estupros, na maioria das vezes, são praticados por pessoas íntimas das mulheres sem nenhum ato de violência física, é reconhecida pelas sobreviventes de estupros de maneira diferente da que é aplicada pelo direito: as mulheres interpretam que o ato sexual do qual tomaram parte e no qual não houve necessariamente violência física foi, na verdade, estupro; o sistema jurídico, pelo outro lado, vê no estupro a expressão de uma violência física que circunstancialmente assumiria a forma de sexo forçado (MACKINNON, 1989) (quando poderia assumir a forma de um espancamento com uma barra de ferro ou alvejamento por projétil de arma de fogo).

$\mathrm{O}$ direito, androcêntrico, centra o crime de estupro na penetração e toma como seu principal "agente" o pênis, embora as destinatárias da norma protetiva sejam as mulheres, que não necessariamente percebem o estupro em termos falocentrados.

Uma vez que no patriarcado a supremacia masculina dita qual deve ser o comportamento sexual das mulheres, parece que a norma que tipifica o estupro está mais voltada para a punição do homem que violou o acesso sexual exclusivo de outro (atual ou futuro) do que para a liberdade sexual das mulheres.

Caso o consentimento, marcador da existência ou não do estupro, existisse para fortalecer o controle das mulheres sobre sua própria sexualidade, não teria sido tão amplamente aceita a tese da exclusão de ilicitude do estupro marital (como um dia já foi no Brasil ${ }^{14}$ ) e, afirma MacKinnon, meninas com idade inferior à legal para o consentimento sexual poderiam exercer sua sexualidade.

\footnotetext{
${ }^{14}$ Já se sustentou que "as relações sexuais são pertinentes à vida conjugal, constituindo direito e dever recíproco dos que casam. $\mathrm{O}$ marido tem direito à posse sexual da mulher, ao qual ela não pode se opor. Casando-se, dormindo sob o mesmo teto, aceitando a vida em comum, a mulher não se pode furtar ao congresso sexual, cujo fim mais nobre é o da perpetuação da espécie. A violência por parte do marido não constituiria, em princípio, crime de estupro, desde que a razão da esposa para não aceder à união sexual seja mero capricho ou fútil motivo, podendo, todavia, ele responder por excesso cometido". (NORONHA, 2002, p. 70)
} 
O direito, porém, estabelece quais são as pessoas que não podem fazer sexo (meninas) e as que devem fazê-lo (casadas), colocando as demais (não meninas e não casadas) em áreas paralelas a essas, de modo que somente as mulheres virgens (como seriam as meninas) possam ser consideradas estupráveis (o que constitui também uma maneira de erotizar meninas) e que as mulheres não virgens (como seriam as casadas) não tenham nada a perder com o estupro por já terem feito sexo antes. (MACKINNON, 1983)

Com isso, na prática, somente as estupráveis estão protegidas por não serem capazes de consentir, enquanto as não estupráveis concedem tacitamente seu consentimento, especialmente se o acusado as conhece por ser marido ou namorado.

Embora seja cada vez menos aceito o estupro marital, tal mudança não parece decorrer do fortalecimento da posição das mulheres na sociedade patriarcal, mas de "um ajuste jurídico ao fato social de que o sexo heterossexual vem sendo crescentemente visto como não restrito à família". (MACKINNON, 1983, p. 648, tradução nossa), ou seja, os maridos podem fazer sexo com outras mulheres e não precisam mais estuprar suas esposas.

Chamar estupro de violência, não de sexo, permite escapar, no momento em que mais parecem se confrontar, à questão de quem controla a sexualidade da mulher e da dinâmica dominação/submissão que a definiu. Quando o sexo é violento, as mulheres podemos ter perdido o controle do que é feito a nós, mas a ausência de força não garante a presença daquele controle. (MACKINNON, 1983, p. 650, tradução nossa)

É difundida entre os homens a percepção de que seria menos ruim ser estuprada por alguém próximo do que por um estranho e não é coincidência que a maioria dos estupros seja praticada justamente por esses conhecidos. É inevitável a conclusão de que essa forma de pensamento é orientada pela ideologia patriarcal.

O direito, para diferenciar o sexo forçado do sexo consentido, adota o critério masculino do nível de força, sem atentar para o que as vozes das vítimas concebem como estupro. Assim, diante de casos em que a força utilizada não é considerada suficiente para constituir a violência física que o direito entende necessária para a demonstração da negativa de consentimento, entendese que o sexo aceitável pode admitir o uso de muita força. Se o estupro, portanto, parece sexo consentido, não será interpretado como estupro. 
A interpretação jurídica ignora a sexualidade, no patriarcado, como relação de poder de homens sobre mulheres e utiliza, para detectar o estupro, o desvelamento do que a mulher queria e do que o homem entendeu que ela queria a partir do critério da força física.

Sendo as mulheres o grupo contra as quais o grupo dos homens sistematicamente pratica o estupro, este deveria ser definido pela perspectiva das mulheres; porém, no patriarcado, a concepção sobre a realidade e a objetividade do estupro são delineadas de acordo com a visão masculina, sendo irrelevante que, do ponto de vista das mulheres, como grupo subordinado, a ausência de qualquer violência física também signifique estupro.

\footnotetext{
Muitas mulheres são estupradas por homens que sabem o significado de seus atos para as mulheres e continuam assim mesmo. Mas mulheres também são violadas todos os dias por homens que não têm a menor ideia do significado de seus atos para as mulheres. Para eles, é sexo. Portanto, para o direito, é sexo. Essa é a realidade única do que aconteceu. (MacKinnon, 1983, p. 652-653, tradução nossa)
}

Quando o agressor sustenta que acreditou erroneamente no consentimento da mulher, a mensagem que enuncia é de que ela não foi estuprada porque ele acreditou que ela tivesse consentido, ou seja, houve apenas uma relação sexual sem nenhum prejuízo, uma vez que mulheres consentem com sexo cotidianamente e, não sendo mais virgens, nada têm a perder.

Como é a ideologia patriarcal que orienta os costumes sexuais de homens e mulheres, o estupro é definido a partir do que os homens entendem que as mulheres deveriam considerar estupro e não, o que elas consideram. Assim, a configuração ideal do estupro teria uma jovem, branca, virgem e de classe média (ou alta) que expressamente dissesse a palavra "não" e se digladiasse ferozmente contra um homem adulto, negro e de classe baixa.

Qualquer descrição diferente levantaria suspeitas sobre a existência do estupro e levaria à interpretação de que a mulher teria dado seu consentimento. Essa "cegueira" masculina integra o condicionamento social dos homens para a ignorância sobre a comunicação das mulheres enquanto grupo subordinado.

Como os homens associam o estupro a um ato de violência física grave praticada por um estranho contra uma mulher por meio do sexo, faz sentido que acreditem também que mulheres forjam acusações de estupro depois de fazem sexo consentido, pois, para eles, nada além disso é considerado estupro. "Uma vez que eles raramente consideram que sua experiência do real seja 
qualquer coisa além da realidade, eles só podem explicar a versão da mulher como maliciosamente inventada". (MACKINNON, 1983, p. 653, tradução nossa)

Além da ficção das falsas acusações de estupro, os homens também acreditam que é difícil provar que o estupro não aconteceu se uma mulher os acusa, embora a grande maioria dos registros de ocorrência por estupro não resulte em condenação penal. Para MacKinnon, essa preocupação masculina se origina do fato de que quando uma mulher afirma a existência de um estupro manifesta sua própria experiência daquela aquela relação sexual e, sobre isso, o homem não tem controle.

$\mathrm{O}$ direito, assim, concebe como dano aquilo que a perspectiva masculina dominante entende como dano, isto é, haverá estupro se ocorrer a prática de relação sexual cuja ausência de consentimento possa ser constatada pelo nível de força empregado. Por outro lado, absolve os estupradores que não perceberam, segundo seu próprio ponto de vista condicionado, que as mulheres, no patriarcado, não dissentem somente por meio da resistência física. (MACKINNON, 1983)

Não há como se chegar à objetividade do estupro no patriarcado, pois os homens, grupo dominante, concebem o estupro de forma vinculada à sua própria perspectiva e de maneira diferente da perspectiva das mulheres, grupo dominado sobre o qual recai o comportamento daqueles.

O que é razoável para um homem acreditar no que concerne ao desejo da mulher por sexo quando a heterossexualidade é compulsória? A subjetividade de quem se torna a objetividade "do que aconteceu"? É uma questão de significado social, ou seja, uma questão de política sexual. (MacKinnon, 1989, p. 183, tradução nossa)

Faz parte da socialização feminina a imposição para que mulheres pareçam desejáveis aos homens, o que, em vez de significar o poder de determinar se haverá ou não relação sexual (consentimento), consiste em verdadeiro disfarce para uma postura passiva, na qual a mulher aguarda a aproximação do homem. Assim, se não houver aproximação do homem, não haverá sexo. 
São o olhar masculino e as formas masculinas de apreender a realidade que, no tribunal masculino ${ }^{15}$, determinam a existência ou a inexistência de violência sexual praticada contra a mulher em um contexto em que os comportamentos sociais e sexuais aceitos são orientados pela supremacia masculina ${ }^{16}$.

Considerar que, em uma sociedade estruturada a partir da divisão hierárquica dos sexos, há terreno plano nos níveis social, emocional, psicológico e até econômico é ignorar que a questão do consentimento entre homens e mulheres não se desenvolve entre integrantes de grupos de igual poder e sujeitos a idênticas consequências.

\section{CONSIDERAÇÕES FINAIS}

15 Não se refere aqui à exclusividade de membros homens de um tribunal, mas à hegemonia dos métodos de compreensão ligados à supremacia masculina no saber jurídico. A propósito, até a data de 25 de agosto de 2016 o Tribunal de Justiça do Estado do Rio de Janeiro contava com 58 desembargadoras e 122 desembargadores, o que corresponde a uma representatividade de 32,3\% de mulheres e 67,7\% de homens na composição da segunda instância judiciária do Estado. Disponível em: <http://www4.tjrj.jus.br/camarasweb/listaDesembargadores.aspx>. Acesso em: 25 de agosto de 2016.

${ }^{16}$ Pode-se tomar como exemplo do ponto de vista masculino do direito o julgamento histórico do Recurso Especial $\mathrm{n}^{\circ}$ 1.517/1991 pelo Superior Tribunal de Justiça, que somente no ano de 1991 repudiou a tese da legítima defesa da honra veiculada pelo marido acusado de matar a esposa e o homem com ela encontrado: "Recurso Especial. Tribunal do Júri. Duplo homicídio praticado pelo marido que surpreende sua esposa em flagrante adultério. Hipótese em que não se configura legítima defesa da honra. Decisão que se anula por manifesta contrariedade à prova dos autos (art. 593, parágrafo $3^{\circ}$ do $\mathrm{CPP}$ ). Não há ofensa à honra do marido pelo adultério da esposa, desde que não existe essa honra conjugal. Ela é pessoal, própria de cada um dos cônjuges. O marido que mata sua mulher para conservar um falso crédito, na verdade, age em momento de transtorno mental transitório, de acordo com a lição de Jimenez de Asúa (El criminalista, ed. Zavalia, B. Aires, 1960, T. IV, p. 34), desde que não se comprove ato de deliberada vingança. O adultério não coloca o marido ofendido em estado de legítima defesa pela sua incompatibilidade com os requisitos do art. 25 do Código Penal. A prova dos autos conduz a autoria e a materialidade do duplo homicídio (mulher e amante), não a pretendida legitimidade da ação delituosa do marido. A lei civil aponta os caminhos da separação e do divórcio. Nada justifica matar a mulher que, ao adulterar, não preservou a sua própria honra. Nesta fase do processo, não se há de falar em ofensa a soberania do Júri, desde que os seus veredictos só se tornam invioláveis quando não há mais possibilidade de apelação. Não é o caso dos autos, submetidos, ainda, a regra do artigo 593, parágrafo $3^{\circ}$ do CPP. Recurso provido para cassar a decisão do Júri e o acórdão recorrido, para sujeitar o réu a novo julgamento.” (grifo nosso) (STJ - REsp: 1517 PR 1989/0012160-0, Relator: Ministro JOSE CANDIDO DE CARVALHO FILHO, Data de Julgamento: 11/03/1991, T6 - SEXTA TURMA, Data de Publicação: DJ 15.04.1991 p. 4309, JTS vol. 24 p. 64, RJM vol. 114 p. 192, RSTJ vol. 20 p. 175). Infere-se de tal fragmento que somente na última década do século XX o Tribunal Superior encarregado de uniformizar a interpretação da lei federal no Brasil entendeu, por maioria, que o homicídio praticado pelo marido, motivado por traição conjugal, não seria compreendido pelo direito como comportamento justificado. Apesar de não dar acolhida ao argumento mencionado, o julgado não se limitou a tratar da conduta do marido acusado (que entendeu ter agido por "transtorno mental transitório") e deixou clara a leitura do Ministro Relator de que a mulher, "ao adulterar, não preserva sua própria honra". 
O direito, em que pese a exposição de sua feição sexista, segue, majoritariamente, tendendo à conservação da interpretação jurídica que exiba no Estado o espelho da sociedade sem problematizar a divisão hierárquica dos sexos, o que empresta objetividade à epistemologia, dissemina a experiência masculina como a experiência humana e assegura a manutenção das posições de poder já existentes.

As normas formais do Estado iluminam a perspectiva masculina como um verdadeiro projeto político a partir do sexo, constituindo uma ideologia que tem como instrumentos as condições inferiores influentes também nos campos econômico, social, psicológico, emocional etc.

$\mathrm{Na}$ linha da crítica feminista, o discurso jurídico adquire legitimidade e traz invisibilidade para a dominação sexual, de modo que a subordinação das mulheres seja percebida como algo natural e não, socialmente construído com a intenção de assegurar a posição do grupo dominante.

Em contraposição ao patriarcado, a luta política baseada nas experiências concretas das mulheres confronta o direito com seu caráter hegemonicamente masculino, o que não implica, entretanto, a adoção imediata de mudança de perspectiva institucional ${ }^{17}$, menos ainda que mudanças legais possam, por si sós, operar modificações sociais e culturais exterminadoras da discriminação sexual, como já demonstrou a insuficiência do feminismo liberal.

Em virtude de constituir uma crítica que interpreta as relações jurídicas do ponto de vista das mulheres como grupo subordinado, a teoria feminista do direito enxerga que não existe igualdade entre os sexos, mas sim, dinâmica de dominação-subordinação normativa e empírica. Quando a perspectiva masculina começar a ser compreendida como situada, representativa de uma posição específica e não, como objetividade, poderá ser percebido seu modo de fazer o direito funcionar na prática cotidiana, na prestação jurisdicional e na atividade legislativa.

$\mathrm{O}$ alcance de cidadania plena pelas mulheres não pode ser atingido sem passar pelo campo jurídico e, para isso, é necessário que se promova, em vez de adaptação, mudança: "uma nova teoria, uma nova relação entre vida e direito” (MACKINNON, 1989, p. 249, tradução nossa) que

\footnotetext{
${ }^{17} \mathrm{O}$ direito ao aborto é uma demanda feminista de décadas que no Brasil só é admitida nos incisos I e II do artigo 128 do Código Penal, além do acórdão proferido pelo Supremo Tribunal Federal na Ação de Descumprimento de Preceito Fundamental $\mathrm{n}^{\circ}$ 54, que preveem a impunibilidade do aborto necessário e em caso de gravidez resultante de estupro, bem como a inconstitucionalidade da interpretação segundo a qual a interrupção da gravidez de feto anencéfalo é conduta tipificada nos artigos 124, 126, 128, incisos I e II, todos do Código Penal.
} 
contemple a inexistência de neutralidade deste como reflexo de uma política hierárquico-sexual que subordina mulheres a homens no mundo social influenciado pela cultura patriarcal.

\section{REFERÊNCIAS}

BELTRÁN, Elena et al. Feminismos: debates teóricos contemporáneos. 4. ed. Madrid: Alianza Editorial, 2012.

BRASIL. Decreto-lei no 2.848, de 7 de dezembro de 1940. Código Penal. Diário Oficial da União. Brasília, DF, 31 de dezembro de 1940. Disponível em: http://legis.senado.gov.br/legislacao/DetalhaDocumento.action?id=102343. Acesso em: 11 ago. 2016.

Lei $\mathrm{n}^{\mathrm{o}} 12.015$, de 7 de agosto de 2009. Altera o Título VI da Parte Especial do DecretoLei no 2.848, de 7 de dezembro de 1940 - Código Penal, e o art. 1o da Lei no 8.072, de 25 de julho de 1990, que dispõe sobre os crimes hediondos, nos termos do inciso XLIII do art. 5o da Constituição Federal e revoga a Lei no 2.252, de 1 o de julho de 1954, que trata de corrupção de menores. Diário Oficial da União. Brasília, DF, 10 ago. 2009. Disponível em: http://pesquisa.in.gov.br/imprensa/jsp/visualiza/index.jsp?jornal=1\&pagina=1\&data=10/08/2009. Acesso em: 11 ago. 2016.

Superior Tribunal de Justiça. Recurso Especial no 1.517-PR (1989/0012160-0) da $6^{\mathrm{a}}$ Turma. Relator Ministro José Cândido de Carvalho Filho, Data de Julgamento: 11/03/1991, Data de Publicação: DJ 15.04.1991 p. 4309, JTS v. 24, p. 64; RJM v. 114 p 192; RSTJ v. 20 p. 175.

. Supremo Tribunal Federal. Ação de Descumprimento de Preceito Fundamental no 54. Relator Ministro Marco Aurélio. Tribunal Pleno, julgado em 12/04/2012. Acórdão eletrônico DJE no 80, divulgado em 29/04/2013, publicado em 30/04/2013, Revista Trimestral de Jurisprudência do Supremo Tribunal Federal (RTJ), v. 226, p. 11.

DALTON, Clare. Where we stand: observations on the situation of feminist legal thought. Berkeley women's law journal, v. 3, n. 1, p. 1-13, 1989.

DWORKIN, Andrea; MACKINNON, Catharine A. The reasons why: essays on the new civil rights law recognizing pornography as sex discrimination. New York: Women against pornography, 1985. 
HANISCH, Carol. The personal is political. In: FIRESTONE, Shulamith; KOEDT, Anne (eds.). Notes from the second year: women's liberation in 1970: major writings of the radical feminists, New York: Radical Feminism, 1970, p. 76-78.

LANGTON, Rae. Feminism in philosophy. In: JACKSON, Frank; SMITH, Michael (eds.). The Oxford Handbook of Contemporary Analytic Philosophy, Oxford: Oxford University Press, 2005, p. 231-257.

MACKINNON, Catharine A. Feminism, Marxism, Method, and the State: toward feminist jurisprudence. Signs: journal of women in culture and society. Chicago, p. 635-658, Summer of 1983.

. Sexual harassment of working women. New Haven: Yale University Press, 1979.

Toward a feminist theory of the state. Cambridge: Harvard University Press, 1989.

MILLETT, Kate. Sexual Politics. 5th ed. New York: Columbia University Press, Livro eletrônico. Leitor Kindle para iPad versão 4.16, 2016.

NORONHA, Edgard Magalhães. Direito penal. 26. ed. Vol. 3. São Paulo: Saraiva, 2002.

OLSEN, Frances. The sex of law. In: KAIRYS, David (ed.). The politics of law: a progressive critique. 3rd ed. New York: Basic Books, 1998, p. 691-707.

PERROT, Michelle. Os excluídos da história: operários, mulheres e prisioneiros. Rio de Janeiro: Paz e Terra, 1988.

OS ministros de Temer. G1, Rio de Janeiro, 12 de maio de 2016. Disponível em http://especiais.g1.globo.com/politica/2016/ministros-temer/. Acesso em: 10 ago. 2016.

STANTON, Elizabeth Cady; ANTHONY, Susan B.; GAGE, Matilda Joslyn (eds.). History of woman suffrage, v. 1. 2nd ed. Rochester, NY: Charles Mann, 1889.

VOGEL, Lise. Debating difference: feminism, pregnancy and the workplace. Feminist Studies, Maryland, v. 16, n. 1, p. 9-32, Spring, 1990.

WHITMAN, Christina Brooks. Review Essay: feminist jurisprudence. Feminist Studies, Maryland, v. 17, n. 3, p. 493-507, Fall, 1991. 